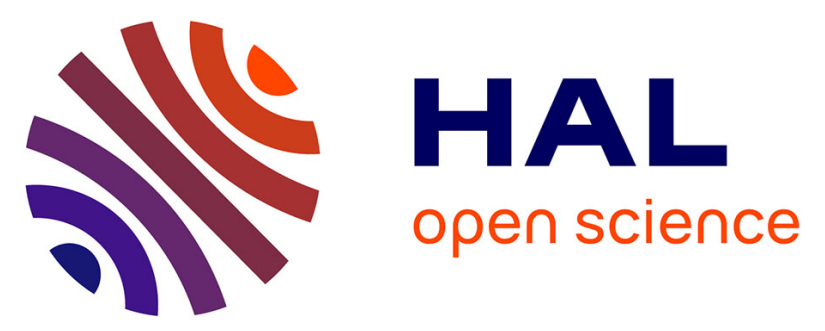

\title{
Probabilistic analysis of pore water pressures of an earth dam using a random finite element approach based on field data
}

\author{
A. Mouyeaux, C. Carvajal, P. Bressolette, L. Peyras, Pierre Breul, C. \\ Bacconnet
}

\section{To cite this version:}

A. Mouyeaux, C. Carvajal, P. Bressolette, L. Peyras, Pierre Breul, et al.. Probabilistic analysis of pore water pressures of an earth dam using a random finite element approach based on field data. Engineering Geology, 2019, 259, pp.12. 10.1016/j.enggeo.2019.105190 . hal-02609467

\section{HAL Id: hal-02609467 https://hal.inrae.fr/hal-02609467}

Submitted on 16 May 2020

HAL is a multi-disciplinary open access archive for the deposit and dissemination of scientific research documents, whether they are published or not. The documents may come from teaching and research institutions in France or abroad, or from public or private research centers.
L'archive ouverte pluridisciplinaire HAL, est destinée au dépôt et à la diffusion de documents scientifiques de niveau recherche, publiés ou non, émanant des établissements d'enseignement et de recherche français ou étrangers, des laboratoires publics ou privés. 
Probabilistic analysis of pore water pressures of an earth dam using a random finite element approach based on field data

Text published in: Engineering Geology 259 (2019) 105190

Anthony Mouyeaux ${ }^{\mathrm{a}, \mathrm{b}}$; Claudio Carvajal $^{\mathrm{a}}{ }^{*}$; Philippe Bressolette ${ }^{\mathrm{b}, \mathrm{c}}$; Laurent Peyras $^{\mathrm{a}}$; Pierre Breul $^{\mathrm{b}, \mathrm{c}} ;$ Claude Bacconnet ${ }^{\mathrm{b}, \mathrm{c}}$

a Irstea, RECOVER, 3275 Route de Cézanne, CS 40061, 13182 Aix-en-Provence Cedex 5, FRANCE.

b Université Clermont-Auvergne, BP 10448, F-63000 Clermont-Ferrand, FRANCE.

${ }^{\mathrm{c}}$ CNRS, UMR 6602, Institut Pascal, F-63171 Aubière, France.

* Corresponding Author

Claudio Carvajal

Irstea, RECOVER, 3275 Route de Cézanne, CS 40061

13182 Aix-en-Provence Cedex 5, FRANCE.

Tel. +33 (0)4.42.66.69.87

E-mail: claudio.carvajal@irstea.fr

Others e-mail addresses:

anthony.mouyeaux@irstea.fr

(A. Mouyeaux)

philippe.bressolette@uca.fr

(P. Bressolette)

laurent.peyras@irstea.fr

(L. Peyras)

pierre.breul@uca.fr

(P. Breul)

claude.bacconnet@uca.fr

(C. Bacconnet) 


\section{ABSTRACT}

2 Knowledge of pore water pressure in an earth dam is crucial for analyzing its mechanical

3 stability. In classical calculations of these pressures, great uncertainty exists regarding the

4 permeability of the materials and the representation of their spatial variability. In this article, a

5 probabilistic analysis of pore water pressures based on field data is performed to represent the

6 permeability with a 2D random field established from statistical and geostatistical analyzes.

7 This random field is introduced in a model based on the Finite Element Method (FEM) and

8 the influence of the spatial variability of permeability on pore water pressure is then studied

9 using Monte-Carlo simulations (MCS).

11 KEYWORDS:

12 Earth dam; Finite element; Spatial variability; Pore water pressure; Random fields, Monte-

13 Carlo simulation 


\section{INTRODUCTION}

Earth dams are structures subjected to risks and their stability must be guaranteed throughout their lifecycle. Three main failure mechanisms exist concerning earth dams: external erosion due to overtopping, internal erosion and sliding of the slope (Foster et al., 2000). The last two failure modes are directly linked to the hydraulic conditions of the flow inside the earth dam, that influence the structure's mechanical stability.

The calculation of the flow through an earth dam is generally performed deterministically, with soil properties considered as constants for a layer of soil of the same type (Gui et al., 2000). However, soils in their natural state are composed of heterogeneous materials with several scales of description (Cho, 2012) and deterministic methods present limits as they do not explicitly consider uncertainties linked to the partial engineer's knowledge of the soil concerned.

In this context, and for several decades, an increasing number of research works have focused on taking into account uncertainties related to soils to calculate flows in earth dams. Researchers tried to improve the methods used to evaluate the reliability of slopes of geotechnical structures (Vanmarcke, 1983; Bergado and Anderson, 1985; Sivakumar Babu and Murphy, 2005; Srivastava et al., 2009). Fenton and Griffiths (1993) used the random finite element method (RFEM) by coupling the finite element method and random field theory via Monte-Carlo Simulations (MCS) for the flow calculation. Numerous other studies were then performed on the problem of flow into a soil by considering the spatial variability of a geotechnical parameter in using random fields (Fenton and Griffiths, 1996, 1997; Griffiths and Fenton, 1997; Gui et al., 2000; Srivastava et al., 2009; Cho, 2012; Liu et al., 2017). Modelling the spatial variability of hydraulic properties of soils (e.g. hydraulic conductivity) could also be meaningful when proceeding coupled hydraulic and mechanical calculation, for studying consolidation issues for example (Huang et al., 2010). 
All these studies provide important information on both the probabilistic analysis to be implemented, and the influence of some parameters on the results obtained as outputs. However, most of these studies mainly deal with theoretical cases considering a hypothetical homogenous earth dam with simplified geometry. Furthermore, the input data used to characterize the material properties in these probabilistic studies were hypothetical data that were not obtained from tests conducted on samples of real soils, except for Smith and Konrad (2011) who presented probabilistic analysis of the spatial variability of permeability using field data. These authors used geostatistical methods to describe the spatial variability of the quantity of fines in the core and predict values at locations into the earth dam where it was not measured.

Another approach to model the spatial variability of the permeability of the fill of an earth dam can involve directly the monitoring pressure measurements and inverse analysis methods (Castelier, 1995). This specific kind of methods does not consider available soil properties data from laboratory and in-situ tests, and they require significant computational efforts. Recent studies consider these data for back analysis as prior information in a Bayesian framework. Zheng et al. (2018) used field measurements to predict the settlement of an embankment. Another work from Yang et al. (2018) proposes a Bayesian approach to use field responses (e.g. pore pressure measurements) to estimate spatially varied hydraulic properties in an embankment. However, this method is applied on an artificial dataset and not on real data.

Based on a study case, the aim of this article is to present a probabilistic analysis of the pore water pressure from the available soil properties dataset of an existing dam. The

61 implemented probabilistic approach incorporates several aspects: i) the analysis of the spatial variability of the physical soil properties data collected during the dam construction phase 
permeability inside the earth dam based on previous analyzes of soil properties; iii) the development of a probabilistic hydraulic model using the random finite element method to characterize the variability of the pore water pressures field.

The manuscript is presented as follows. The methods commonly used for the probabilistic seepage analysis of earth dams are briefly presented in Section 2. Then, Section 3 gives a description of the case study and the available dataset. Section 4 presents a probabilistic analysis to obtain a random field representation of the spatial variability of permeability. Numerical analyzes and results of spatial variability of pore-water pressures are presented in Section 5, and then discussed in Section 6. Finally, the main conclusions are highlighted in Section 7.

\section{SEEPAGE ANALYSIS}

\subsection{Deterministic governing equations solved by FEM}

The flow through a cross section of an earth dam can be defined from the Richards' equation (Richard, 1931):

$$
C(h) \frac{\partial h}{\partial t}=\frac{\partial}{\partial x}\left[K_{x}(\theta) \frac{\partial h}{\partial x}\right]+\frac{\partial}{\partial z}\left[K_{z}(\theta)\left(\frac{\partial h}{\partial z}+1\right)\right]
$$

where $h$ is the hydraulic head $(\mathrm{m}), C$ is the hydraulic capacity $\left(\mathrm{m}^{-1}\right), t$ is time $(\mathrm{s}), \theta$ is the volumetric water content $\left(\mathrm{m}^{3} \cdot \mathrm{m}^{-3}\right)$ and $K_{x}$ and $K_{z}$ are the hydraulic conductivities in the horizontal and vertical directions, respectively.

Eq. (1) involves the permeability at saturation of the porous material. A distinction is made between the horizontal $K_{x}$ and vertical $K_{z}$ permeabilities in the case of anisotropy, by noting $r_{k}=K_{x} K_{K_{z}}$, the anisotropy coefficient. In the hypothesis of a completely saturated soil, the permeability at saturation is assumed to be constant, which simplifies Eq. (1). The saturatedunsaturated behavior of soils can be represented by several empirical relations between the 

equations most often used are those proposed by Van Genuchten (Van Genuchten, 1980):

$$
\begin{gathered}
S_{e}(\psi)=\frac{\theta-\theta_{r}}{\theta_{s}-\theta_{r}}=\frac{1}{\left[1+(\alpha \psi)^{n}\right]^{m}} \quad\left(m=\frac{n-1}{n}, n>1\right) \\
K=K_{\text {sat }} S_{e}(\psi)^{1 / 2}\left[1-\left(1-S_{e}(\psi)^{1 / m}\right)^{m}\right]^{2}
\end{gathered}
$$

in which $\theta_{s}$ and $\theta_{r}$ represent the volumetric water content at saturation and the residual volumetric water content of the soil, respectively. Coefficients $\alpha, n$ and $m$ are the parameters of the retention curve to be fitted. These parameters are necessary for evaluating unsaturated behavior but they are difficult to obtain as they require specific tests to be performed in laboratory (Masekanya 2008; Fredlund and Houston, 2009). These tests are rarely carried out in the framework of designs for the construction of a hydraulic structure.

The saturated-unsaturated flow problem represented by Eq. (1) is generally resolved in the literature using either the finite difference method or the finite element method. In the present article, an iterative finite element model was developed by using an open-ended calculation code which will be presented in the following.

\subsection{Spatial variability modelling}

The spatial variability of soil properties can be efficiently modelled with random field theory, which is more and more used in the literature (Fenton and Griffiths, 1996, 1997; Griffiths and Fenton, 1997; Gui et al., 2000; Srivastava et al., 2009; Cho, 2012; Liu et al., 2017). A detailed development of the theory can be found in Vanmarcke (1983). A random field is a collection of random variables indexed by a spatial variable $\boldsymbol{x}$ depending on one or more reference directions (Sudret and Der Kiureghian, 2000). A Gaussian random field can be fully described by knowing the mean $\mu(\boldsymbol{x})$, the standard deviation $\sigma(\boldsymbol{x})$, and the autocorrelation function. A random field is stationary if the following requirements are followed (Li et al., 2015; Liu et al., 2017): i) the statistical moments are the same over the 
random field domain; ii) the covariance between two values located at two different locations

109 is dependent on the absolute distance between the two points but not on their locations.

110 Stationary random fields are generally used to model the spatial variability of homogenous

111 soils whereas non-stationary fields are suitable for multi-layered soils (Li et al., 2015; Liu et

112 al., 2017). A non-stationary random field can also be decomposed into several stationary

113 random fields.

114 Theoretical autocorrelation functions are usually used to characterize the spatial correlation

115 of soil properties because determining such a function with geostatistical methods is not easy

116 because of the need of a large quantity of statistical data (Li et al., 2015). Nonetheless, these

117 methods have already been used in the framework of earth dams to estimate hydraulic

118 conductivity (Castelier, 1995; Smith and Konrad, 2011). Variability is described by a function

119 of the structure $\gamma(h)$, called a variogram, representing the semi-variance between the

120 deviation of the values taken by two points separated by a distance $h$. In practice, preference

121 is given to an estimator of the theoretical variogram, often called the experimental variogram

$122 \gamma^{*}(h)$, and defined by the following expression:

$$
\gamma^{*}(h)=\frac{1}{2 N(h)} \sum_{i=1}^{N(h)}\left[Z\left(x_{i}+h\right)-Z\left(x_{i}\right)\right]^{2}
$$

$123 N(h)$ is the number of pairs of variable $Z(x)$ separated by distance $h$.

124 A mathematical model is applied to the points representing the experimental variogram. It

125 permits representing either the theoretical variogram directly, or the autocorrelation function,

126 which will allow the generation of the random fields (Vanmarcke, 1983).

127 In this study, stationary Gaussian random fields with exponential autocorrelation function 128 were considered to represent the variability of soil properties measured during compaction 
129

130

132

133

controls. For the autocorrelation function, the autocorrelation distances in the vertical and horizontal directions are defined from a geostatistical analysis of field data.

\subsection{Uncertainties propagation based on MCS}

The finite element method permits a deterministic resolution of the flow equation. The uncertainties of the input data can be modelled as random variables, or as random fields to account for spatial variability of soils. Obtaining a probabilistic response using a RFEM involves a numerical modelling based on the FEM in which one or more input parameters are modelled as random. It permits evaluating the global probabilistic structure of the finite element model's response (Sudret and Der Kiureghian, 2000).

This approach is often used in association with MCS, which remains the only universal method for treating the strongly non-linear and highly variable problems represented by soil properties (Cho, 2012). This method requires a large number of realizations in order to obtain robust statistical characteristics for the output variables.

In this study, MCS is performed to reproduce the deterministic analysis including the simulation of 2D random fields of permeability. MCS allows characterizing the variability of pore water pressures inside the embankment.

\section{DAM STUDIED AND AVAILABLE DATA}

The case studied is an earth dam located in the west of France. It is a pseudo zoned structure with a maximum height of $23 \mathrm{~m}$. The dam body is composed of a core (COR) made of sandy silts which support an upstream shoulder (UPS) and a downstream shoulder (DOS) made of coarse sands formed by the alteration of schists. The downstream shoulder is composed of a material slightly coarser than the one of the upstream shoulder. The foundation is also composed of more or less altered schists whose superficial layers have been purged. A 
152 chimney drain and horizontal toe drains are installed in the downstream shoulder to collect

153 flows. The main cross-section of the structure can be seen in Fig. 1.

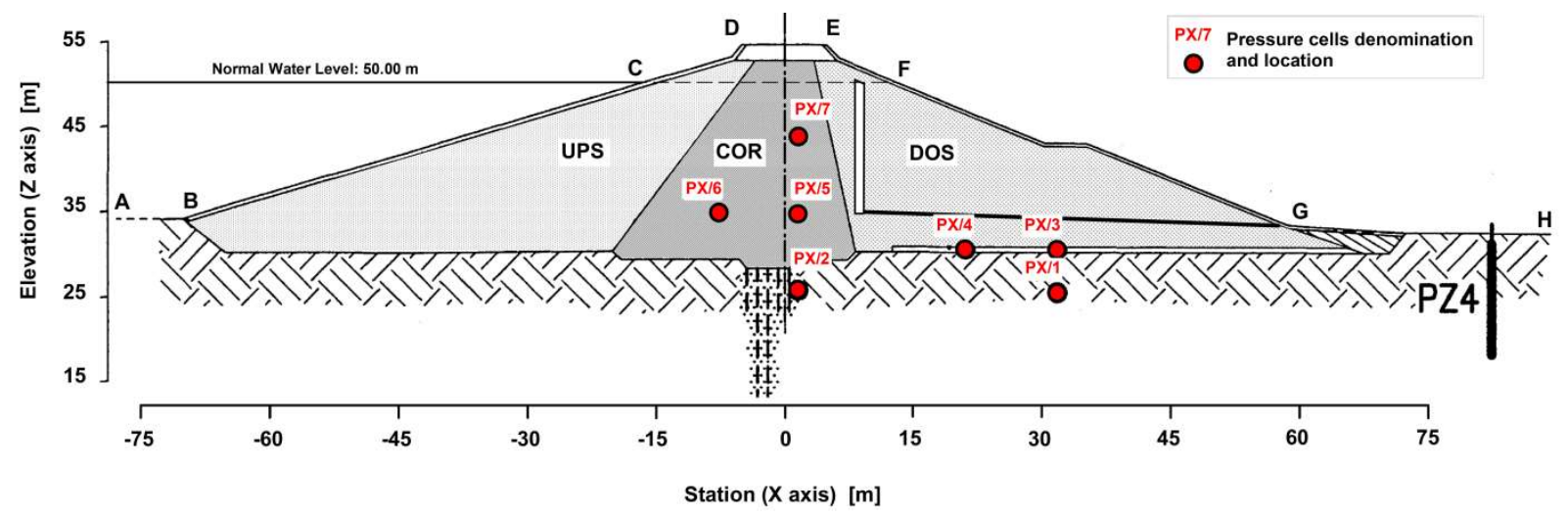

155 Fig. 1. The dam studied: standard cross section and locations of pore water pressure cells.

156 A synthesis of the whole available data for the case study is presented in Table 1. Three 157 main datasets are available in this case study: data obtained from the studies phase, before the 158 construction of the dam; data obtained from a test board realized just before the construction; 159 and finally data obtained during the construction, when controlling the compaction of the fill.

160 During the studies phase, about thirty samples had been taken from borrow pits for the 161 materials composing the structure. They were subjected to grain size distribution analyzes, 162 and other laboratory tests (Atterberg limit measurements, triaxial tests, etc.) were performed 163 on some of them. Permeability tests were also performed, but only on three samples.

164 A test board was defined before the construction of the dam making it possible to identify 165 the behavior of the shoulder material on the basis of seven grain size distribution analyzes and 166 compaction tests.

167 During the construction of the dam, others grain size distribution analyzes were performed 168 on some samples (see Table 1). The entire set of grain size distribution analyzes available is 169 shown in Fig. 2. The band distinguishing the materials used for the UPS/DOS shoulders (in 170 black) can be distinguished from that used for the core (COR) (in red), which had a higher 
171 proportion of fines. The dashed lines curves corresponding to the construction phase include

172 the data obtained from the test board and from the compaction control.

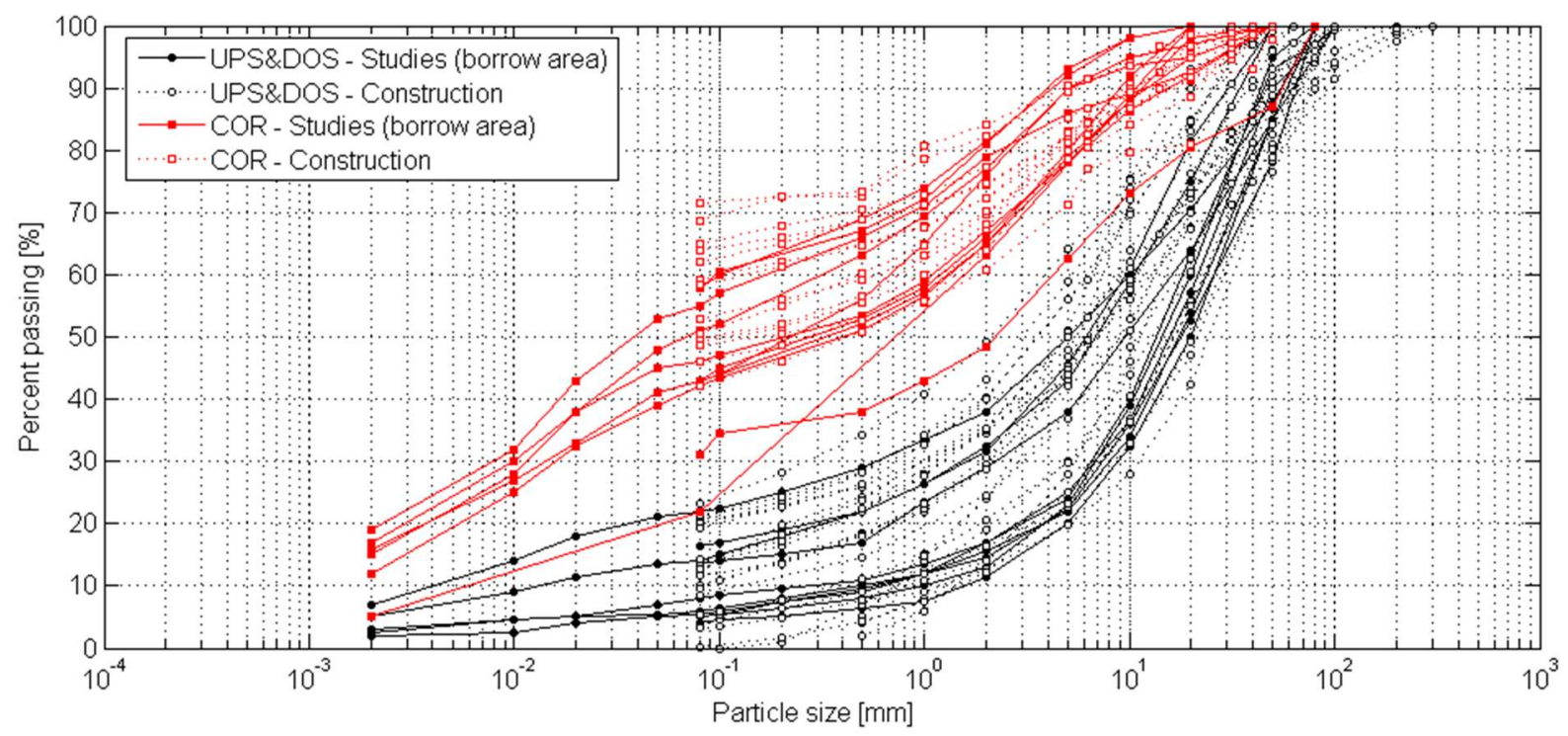

Fig. 2. The dam studied: grain size distribution curves.

175 Table 1 Case study - synthesis of available data.

\begin{tabular}{|c|c|c|c|c|c|c|c|c|c|}
\hline & \multirow[t]{2}{*}{ Soil Type* } & \multicolumn{4}{|c|}{ Number } & \multirow[t]{2}{*}{ Mean } & \multirow[t]{2}{*}{$\operatorname{CoV}(\%)$} & \multirow[t]{2}{*}{ Min } & \multirow[t]{2}{*}{ Max } \\
\hline & & 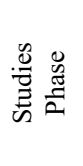 & 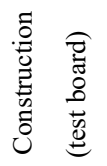 & 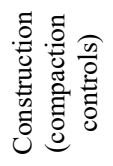 & 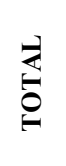 & & & & \\
\hline \multirow{2}{*}{ Samples } & UPS\&DOS & 11 & 11 & 16 & 38 & - & - & - & - \\
\hline & COR & 13 & 0 & 14 & 27 & - & - & - & - \\
\hline \multirow{3}{*}{$\begin{array}{c}\text { Grain Size } \\
\text { Distribution }\end{array}$} & UPS & 10 & 11 & 9 & 30 & - & - & - & - \\
\hline & DOS & 10 & 11 & 7 & 28 & - & - & - & - \\
\hline & COR & 13 & 0 & 14 & 27 & - & - & - & - \\
\hline \multirow{2}{*}{$\begin{array}{c}\text { Plasticity Index } \\
\text { (\%) }\end{array}$} & UPS\&DOS & 3 & 0 & 0 & 3 & 14.2 & 30 & 11 & 19 \\
\hline & COR & 12 & 0 & 0 & 12 & 14.3 & 16 & 10 & 17.5 \\
\hline \multirow{2}{*}{$\begin{array}{c}\text { Liquid Limit } \\
(\%)\end{array}$} & UPS\&DOS & 3 & 0 & 0 & 3 & 48.3 & 13 & 42 & 55 \\
\hline & COR & 12 & 0 & 0 & 12 & 38.2 & 10.3 & 33 & 44 \\
\hline \multirow{2}{*}{$\begin{array}{c}\text { Laboratory } \\
\text { saturated } \\
\text { permeability } \\
\left(\mathrm{m}^{-1} \mathbf{s}^{-1}\right)\end{array}$} & UPS\&DOS & 1 & 0 & 0 & 1 & $5.0 \times 10^{-7}$ & - & $5.0 \times 10^{-7}$ & $5.0 \times 10^{-7}$ \\
\hline & COR & 2 & 0 & 0 & 2 & $3.8 \times 10^{-8}$ & - & $5.0 \times 10^{-9}$ & $7.0 \times 10^{-8}$ \\
\hline \multirow{3}{*}{$\begin{array}{l}\text { Dry density } \\
\quad\left(\mathrm{kg} / \mathrm{m}^{3}\right)\end{array}$} & UPS & 0 & 0 & 376 & 376 & 1991 & 3.2 & 1730 & 2190 \\
\hline & DOS & 0 & 0 & 333 & 333 & 2045 & 3.3 & 1679 & 2196 \\
\hline & $\mathrm{COR}$ & 0 & 0 & 419 & 419 & 1831 & 3.2 & 1655 & 1979 \\
\hline \multirow{3}{*}{$\begin{array}{c}\text { Water content } \\
(\%)\end{array}$} & UPS & 0 & 0 & 376 & 376 & 9.5 & 18 & 5.6 & 15.9 \\
\hline & DOS & 0 & 0 & 333 & 333 & 8.3 & 21.6 & 4.7 & 14.5 \\
\hline & COR & 0 & 0 & 419 & 419 & 15.3 & 13.3 & 9.6 & 21.7 \\
\hline
\end{tabular}

176 *UPS\&DOS: Coarse sands (shoulders material); COR: Sandy silt (core material) 
The dry density and water content after compaction were controlled during the

178 construction of the dam. The dry density was measured in situ with a gamma-densimeter. In

179 all, more than a thousand measurements were performed in the three zones (UPS: 376, COR:

180 419, DOS: 333, respectively). The control measures were compared to the results of the

181 Proctor tests performed periodically during construction.

182 An additional system was installed for the dam studied during its construction to locate the

183 compaction control measurements in space (according to the three axes). Therefore, a large

184 number of dry density measures with relatively precise localization in space is available.

185 Despite the fact that not all the measures were geo-located, a large sample was nonetheless

186 available (UPS: 248, COR: 381, DOS: 272, respectively). Fig. 3 shows the location of data in

187 different planes.

188 Finally, the hydraulic behavior of the dam is monitored by different devices that include

189 cells for measuring pore water pressure installed in the earth fill and into the foundation, and

190 piezometers located on the banks and the downstream toe. The pressure cells are mainly

191 arranged in three profiles, each profile comprising seven cells as described in Fig. 1. The cells

192 are denoted $\mathrm{PX} / \mathrm{Y}$; with $\mathrm{X}=1$ to 3 corresponding to the profile index, and $\mathrm{Y}=1$ to 7

193 corresponding to the location of the cell on one profile (see Fig. 1). 

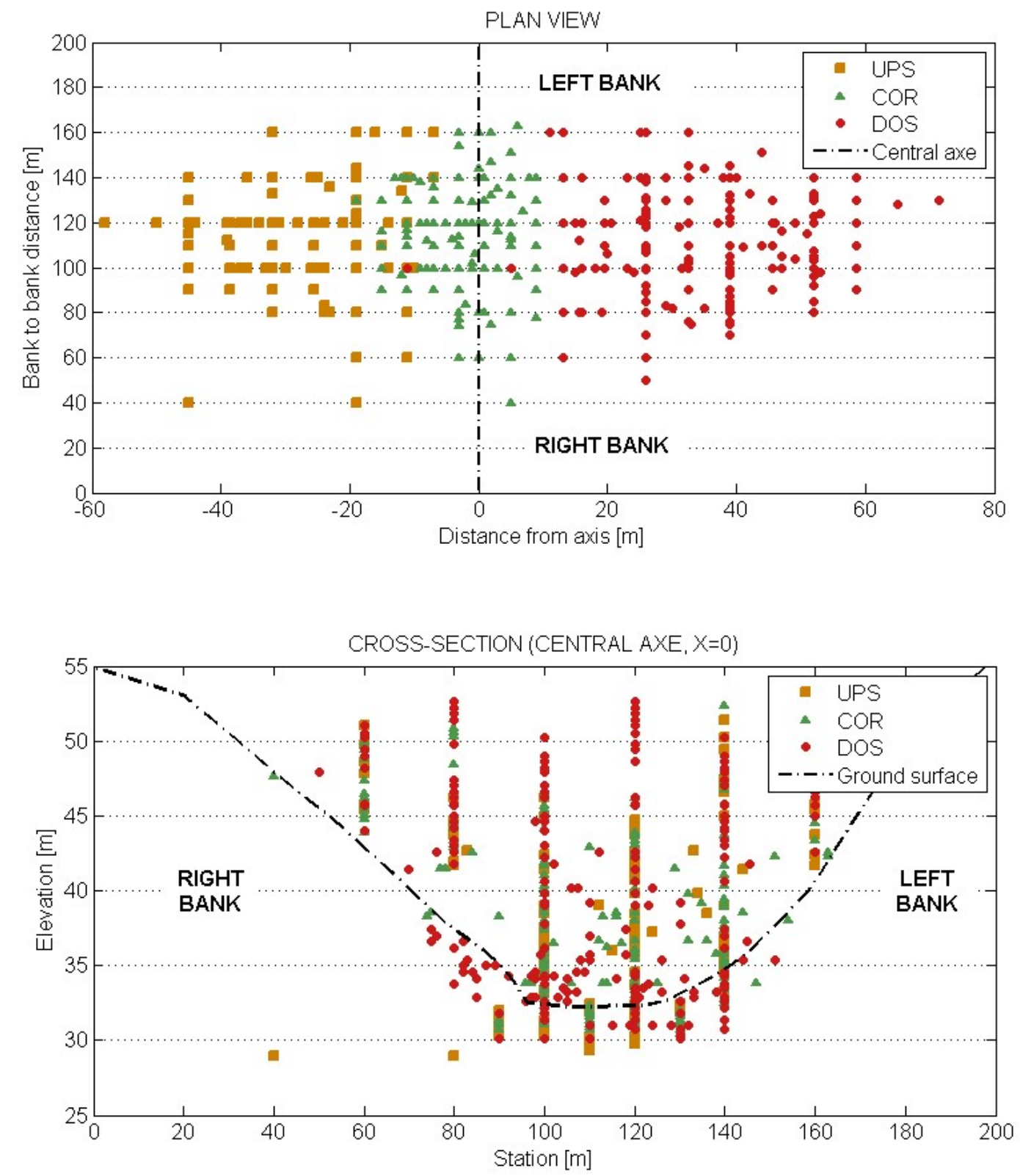

195 Fig. 3. Location of compaction control measurements.

\section{MODELLING OF THE SPATIAL VARIABILITY OF THE CASE STUDY SOIL PROPERTIES}

198 This section presents an overview of the probabilistic modelling of permeability applied on

199 the case study using available soil properties data. After collecting and analyzing the available

200 data on the dam, the modelling of the spatial variability of the permeability was carried out in

201 this study according to the following steps: 
- choose a suitable method for predicting permeability according to the specific soils forming the different zones of the embankment and the quantity and type of data available.

- perform a statistical analysis of available data in order to model the different parameters taking part into the chosen prediction method by random variables. horizontal and vertical directions.

- use previous statistical and geostatistical analyzes to obtain a random field of permeability.

\subsection{Choice of a method for predicting permeability}

213 Very few permeability measurements are available to characterize its variability. In this 214 study, spatial variability will be analyzed using a permeability prediction method from the 215 available data. A review of several methods published in the literature for predicting the 216 permeability has been established by Chapuis (2012). Theses prediction methods are mostly 217 specific to a type of soil, either plastic (clays) or non-plastic (sands).

218 The analysis of the data presented above (see Table 1) shows that the soils used to 219 construct the shoulders (UPS and DOS) and core (COR) of the dam under study have a 220 certain plasticity $\left(I_{P}\right.$ between 10 and 20) and they are composed of both fine particles and 221 coarse elements.

222 Then, the prediction method chosen in this application is the one described by Eq. (5), 223 corresponding to a method developed by Chapuis and Aubertin (2003) based on the Kozeny224 Carman equation. This method is beneficial because it can be used for soils presenting 
225 fractions of fine and coarse materials. In addition, its input parameters can be estimated from 226 the available data.

$$
\log \left(K_{\text {sat }}\right)=0.5+\log \left(\frac{e^{3}}{(1+e) G_{s}^{2} S_{s}^{2}}\right)
$$

Thus, this predictive method needs to give a probabilistic modelling of two parameters:

228 the void ratio $e$ and the specific surface $S_{S}$. This is done in the next step.

229

230

231

232

233

\subsection{Statistical analysis of available data}

The probabilistic modelling of the void ratio is directly done in linking the void ratio with the dry density by a basic soil mechanics formula, $e=\rho_{S} / \rho_{d}-1$, introducing the solid density of the grains $\rho_{S}$ which can be considered constant for soils of the same nature. As compaction control measurements (dry density) are available in sufficient number, as seen in the previous section, the statistical analysis can be easily performed. The statistic parameters of the dry density distributions in the three zones are also shown in Table 1 . The average of the dry densities for the shoulder materials is close to $2000 \mathrm{~kg} / \mathrm{m}^{3}$, but is lower for the core material $\left(1830 \mathrm{~kg} / \mathrm{m}^{3}\right)$. These distributions can be represented by a normal distribution $\left(\chi^{2}\right.$ test). However, a truncated normal distribution is adopted in order to avoid erroneous values and to get realizations which stay within the range of measured values.

\section{Concerning the specific surface, the representation as a random variable is less easy} because no measurement is available in this particular case. Methods have been developed to estimate this parameter based on either the grain size distribution curve (GSDC) (Chapuis and Legare, 1992; Fooladmand; 2011) or the liquid limit (Chapuis and Aubertin, 2003; Dolinar, 2009) depending on the type of soil. In the case of the studied dam, the shoulder and core soils were composed of both fine particles and coarse elements, with proportions differing according to whether the silty sands of the core (COR) or the coarse sands of the shoulders 
(UPS and DOS) were considered. Thus, the specific surface of these materials is calculated in 248 this study by combining both approaches.

Firstly, a specific surface $S_{S_{-} G S D C}$ is estimated with the method proposed by Chapuis and 250 Legare (1992) based on the grain size distribution curves available for the studied dam. Fig. 2 251 shows however that not all the curves were evaluated with the same number of sieves.

252 A methodology proposed by Fredlund et al. (2000) allows homogenizing and standardizing 253 the grain size distribution curves in giving two mathematical representations (unimodal and 254 bimodal) of these curves. In order to homogenize the number of passing percentages for each 255 diameter, these two forms were fitted to each available grain size distribution curve. Fig. 4 256 shows an example of fit to a grain size distribution curve obtained from sample F05 of sandy 257 silt.

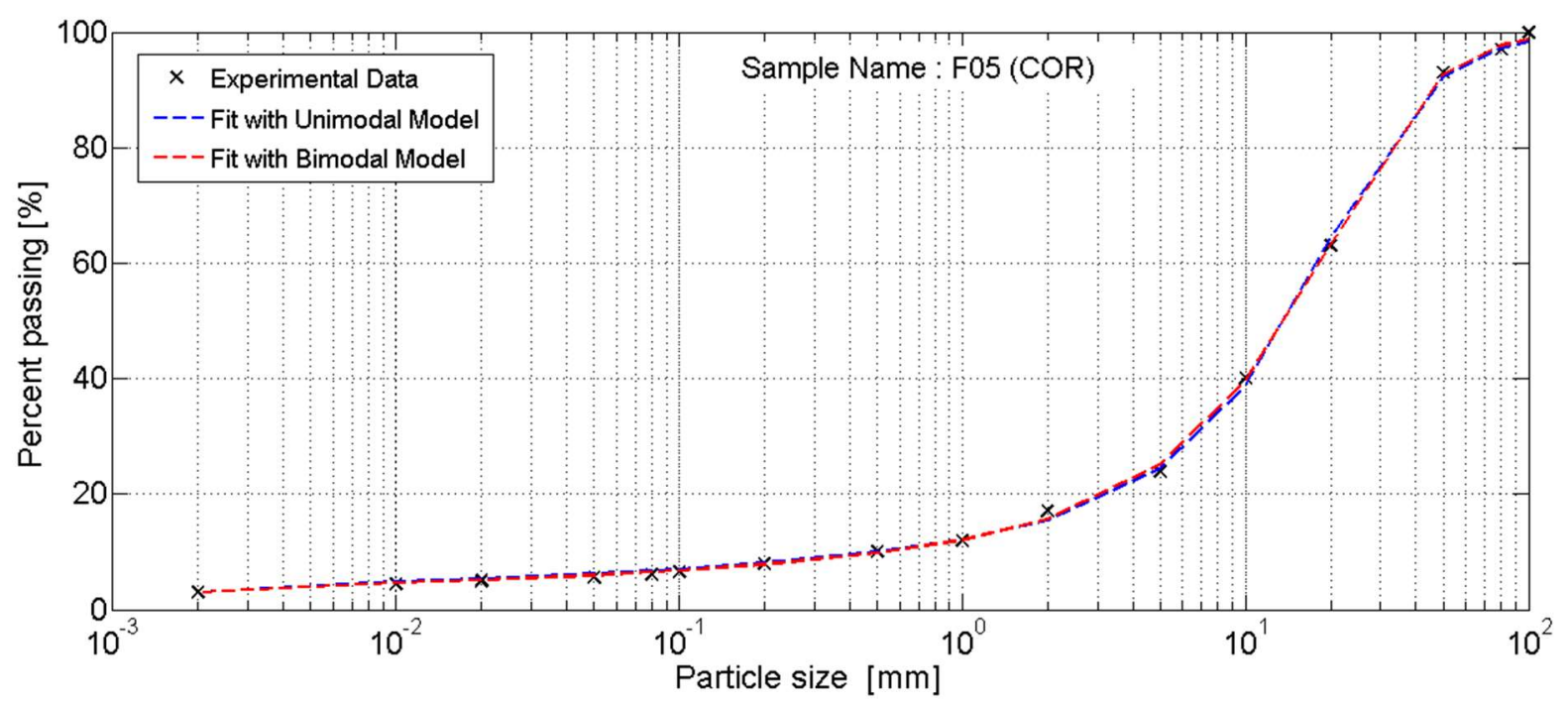

259 Fig. 4. Example of fitting the two forms of the Fredlund et al. (2000) equation - Test F05.

Then, a set of 24 diameters between $0.2 \mu \mathrm{m}$ and $300 \mathrm{~mm}$ is chosen (see Fig 5.). It makes it 261 possible to represent the full range of grain size distribution. The sieve passing percentages were calculated for each of the 24 diameters and for each fitted grain size distribution curve. In the case of the shoulder materials (UPS\&DOS), the sample of grain size distribution 
analyzes was divided into two groups according to whether the samples were taken from the

265 UPS or the DOS during the construction phase. Among the grain size distribution analyzes

266 available for the shoulder materials (see Table 1), 30 (resp. 28) are used to described the grain

267 size distribution of UPS (resp. DOS). Regarding COR, the 27 available grain size distribution

268 curves were directly used.

By calculating the mean and the standard deviation of the distributions obtained for each

270 diameter for the three zones, and by assuming that they all followed a truncated normal

271 distribution for reasons explained above, it was possible to represent each passing percentage

272 by a random variable. The results obtained for diameters $d=2 \mathrm{~mm}, \mathrm{~d}=80 \mu \mathrm{m}, \mathrm{d}=2 \mu \mathrm{m}$ and

$273 \mathrm{~d}=0.2 \mu \mathrm{m}$ are described in Table 2.

Table 2 Statistical properties considered in the probabilistic approach.

\begin{tabular}{|c|c|c|c|c|c|c|}
\hline & Soil Type* & Distribution & Mean & $\operatorname{CoV}(\%)$ & Min & Max \\
\hline \multirow{3}{*}{$\begin{array}{l}\text { Percent Passing } \\
\mathrm{d}=\mathbf{2} \mathrm{mm}(\%)\end{array}$} & UPS & \multirow{3}{*}{ Truncated Normal } & 28.6 & 37.4 & 11.5 & 49.3 \\
\hline & $\mathrm{COR}$ & & 71.5 & 11.3 & 48.5 & 84.2 \\
\hline & DOS & & 23.2 & 40.0 & 11.5 & 43.2 \\
\hline \multirow{3}{*}{$\begin{array}{l}\text { Percent Passing } \\
\mathrm{d}=\mathbf{8 0} \mu \mathrm{m}(\%)\end{array}$} & UPS & \multirow{3}{*}{ Truncated Normal } & 12.6 & 52.6 & 2.2 & 23.2 \\
\hline & $\mathrm{COR}$ & & 51.6 & 17.8 & 32.0 & 71.6 \\
\hline & DOS & & 8.6 & 65.8 & 1.11 & 22.0 \\
\hline \multirow{3}{*}{$\begin{array}{l}\text { Percent Passing } \\
\mathrm{d}=2 \mu \mathrm{m}(\%)\end{array}$} & UPS & \multirow{3}{*}{ Truncated Normal } & 7.4 & 67.2 & 0.9 & 15.8 \\
\hline & $\mathrm{COR}$ & & 39.9 & 41.1 & 12.0 & 71.5 \\
\hline & DOS & & 4.7 & 74 & 0.3 & 13.1 \\
\hline \multirow{3}{*}{$\begin{array}{l}\text { Percent Passing } \\
\mathrm{d}=0.2 \mu \mathrm{m}(\%)\end{array}$} & UPS & \multirow{3}{*}{ Truncated Normal } & 1.0 & 67 & 0.09 & 2.1 \\
\hline & COR & & 5.6 & 48.1 & 1.2 & 10.9 \\
\hline & DOS & & 0.6 & 73.6 & 0.00 & 1.7 \\
\hline \multirow{2}{*}{ Coefficient $\alpha$} & UPS\&DOS & & 0.194 & & & \\
\hline & COR & & 0.238 & & & \\
\hline \multirow{2}{*}{ Coefficient n } & UPS\&DOS & & 1.441 & & & \\
\hline & COR & & 1.332 & & & \\
\hline \multirow{2}{*}{ Coefficient m } & UPS\&DOS & & 0.306 & & & \\
\hline & COR & & 0.249 & & & \\
\hline \multirow{2}{*}{$\begin{array}{l}\text { Anisotropy coefficient } \\
\qquad r_{k}=K_{x} / K_{z}\end{array}$} & UPS\&DOS & \multirow{2}{*}{ Truncated Normal } & $2^{\ddagger}$ & 50.0 & 1 & 15 \\
\hline & COR & & 5 & 50.0 & 1 & 15 \\
\hline
\end{tabular}

276 Finally, this treatment permitted performing the random sampling of a grain size

277 distribution curve corresponding to the materials composing the three zones of the studied 
structure. By applying random sampling to the passing percentages relating to each of the

279 diameters and by conforming to the increasing slope of the curve, it was possible to build a set 280 of grain size distribution curves for the materials of each zone. Fig. 5 shows the bands in 281 which these curves could be sampled.

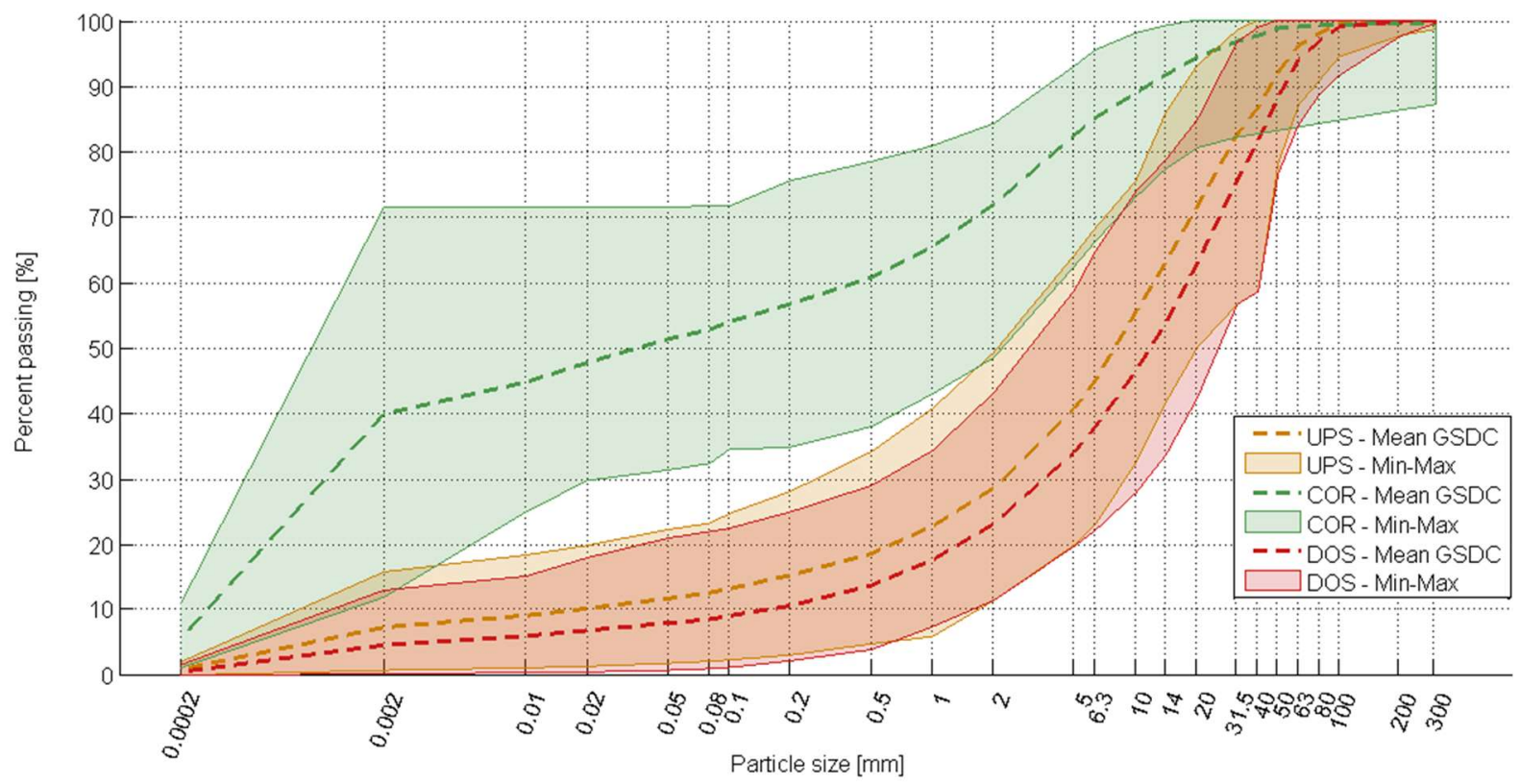

Fig. 5. Bands obtained for the random sampling of GSDC for the materials of each zone (UPS, DOS and COR).

Secondly, a specific surface $S_{S_{-} L L}$ is estimated based on the liquid limit with the empirical relation developed by Chapuis and Aubertin (2003). Regarding the liquid limit, Table 1 shows that they were only measured for a very small number of samples for each type of soil in the case study. However, theirs values were relatively homogeneous. It is assumed that the liquid limit could be represented for each soil (UPS\&DOS and COR), here again by a truncated normal distribution whose statistical characteristics are presented in Table 1.

The two values of specific surface $S_{S_{-} G S D C}$ and $S_{S_{-} L L}$ obtained were then weighted as a 292 function of the fraction of fines $p$ corresponding to the passing percentages for a diameter of $2930.2 \mu \mathrm{m}$. This limit corresponds to the physical limit separating the granular phase from the colloidal phase (Pilot et al., 1970). 


\subsection{Geostatistical analysis of compaction control measurements}

At this stage, the saturated permeability of the materials composing the earth dam could be randomly modelled from the available data as a random variable. Its spatial variability within the earth dam can be obtained from that of the dry density, which is measured layer by layer by the compaction controls performed during its construction. In this case study, a large number of these measures were available and most of them were clearly located in space, thereby enabling a geostatistical analysis (cf. section 3).

A geostatistical analysis was then performed on the density measures of each zone of the dam (UPS, COR and DOS). The experimental variograms were calculated in the horizontal and vertical directions through the cross-section of the dam. A variographic model was then fitted to the six ( 3 zones $\times 2$ directions) calculated experimental variograms. The exponential model was chosen from the models analyzed by associating a nugget effect. Fig. 6 shows the experimental variogram calculated for the downstream shoulder (DOS) in the horizontal and vertical directions, as well as the theoretical variograms fitted to them.

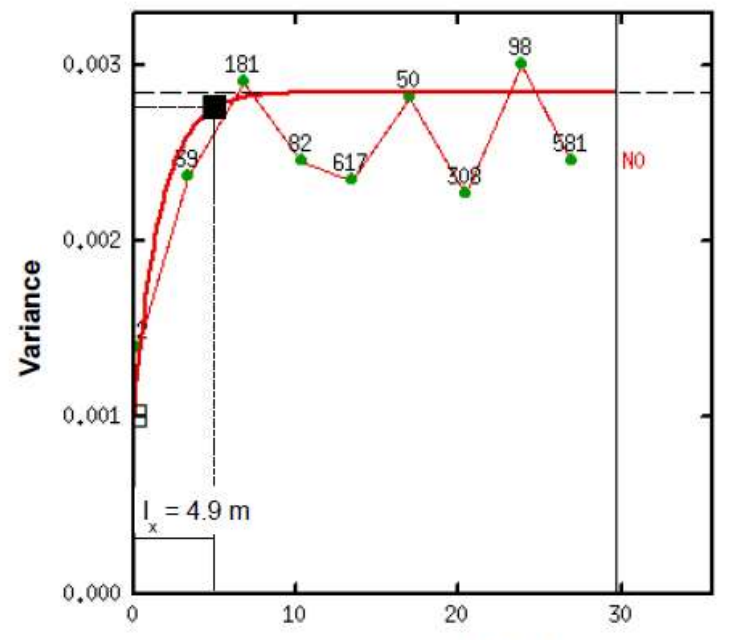

Distance ( $X$ axis) [m]

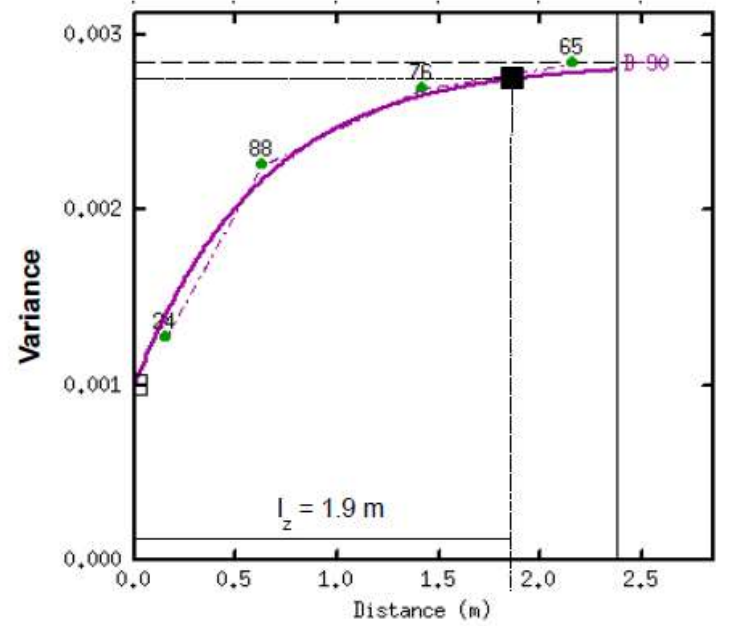

Distance ( $Z$ axis) [m]

Fig. 6. Experimental variograms in the horizontal (left) and vertical (right) directions for the

311 downstream shoulder (DOS). 
The fitted model could be used to calculate the range of each directional variogram, which

313 can be likened to the correlation length between the measures. Table 3 details the results

314 obtained from the geostatistical analysis.

315 Table 3 Results of the geostatistical analysis of compaction control measurements (dry 316 density).

\begin{tabular}{cccccc}
\hline $\boldsymbol{\rho}_{\boldsymbol{d}}\left(\mathbf{t} / \mathbf{m}^{3}\right)$ & Mean & Variance & $\begin{array}{c}\text { Nugget } \\
\text { effect }\end{array}$ & $\begin{array}{c}\text { Correlation } \\
\text { length } \boldsymbol{l}_{\boldsymbol{X}}(\mathbf{m})\end{array}$ & $\begin{array}{c}\text { Correlation } \\
\text { length } \boldsymbol{l}_{\boldsymbol{Z}}(\mathbf{m})\end{array}$ \\
\hline $\mathrm{UPS}$ & 2.00 & $3.5 \times 10^{-3}$ & $1.6 \times 10^{-3}$ & 78.1 & 7.8 \\
\hline COR & 1.83 & $3.6 \times 10^{-3}$ & $8.6 \times 10^{-4}$ & 13.0 & 1.5 \\
\hline DOS & 2.05 & $2.8 \times 10^{-3}$ & $1.0 \times 10^{-3}$ & 4.9 & 1.9
\end{tabular}

318 The correlation lengths in the horizontal direction (X) are significantly longer than in the 319 vertical direction (Z). A more important continuity appears in UPS with longer correlation 320 lengths of about $80 \mathrm{~m}$ horizontally and $10 \mathrm{~m}$ vertically. This lower variability could be 321 explained by a better selection of material composing the UPS and to particular attention 322 being made to the construction of this zone of the dam.

323 The nugget effect corresponded to about half the variance for the upstream shoulder (UPS) 324 and to a slight lower fraction for the downstream shoulder (DOS) and the core (COR). The 325 nugget effect can be attributed to the mixture of the materials during their excavation from the 326 borrow pits. In this case, it is considered as a microstructure whose scale is less than the 327 sampling step.

\subsection{Random field of permeability modelling}

329 The results of the geostatistical analysis were then used to simulate a random field of dry

330 density. An exponential correlation function was used. Gaussian random fields of dry density 331 were generated for each of the zones of the dam (UPS, COR and DOS) on the basis of means, 332 standard deviations and correlation lengths calculated from the distributions of compaction 333 control measures described in previous section. The simulation was performed using directly 
334 the turning bands method with an internal generator of the finite element code Cast3M, which

335 is briefly presented in the next section.

336 Once the random field of dry density is generated over the nodes of the finite element mesh

337 of the structure, Eq. (5) is used to transform the dry density random field into the permeability 338 random field. The specific surface is then modelled as a random variable according to the 339 methodology described in the previous subsection.

340 Fig. 7 illustrates one realization of a random field of permeability obtained using the 341 procedure explained above.

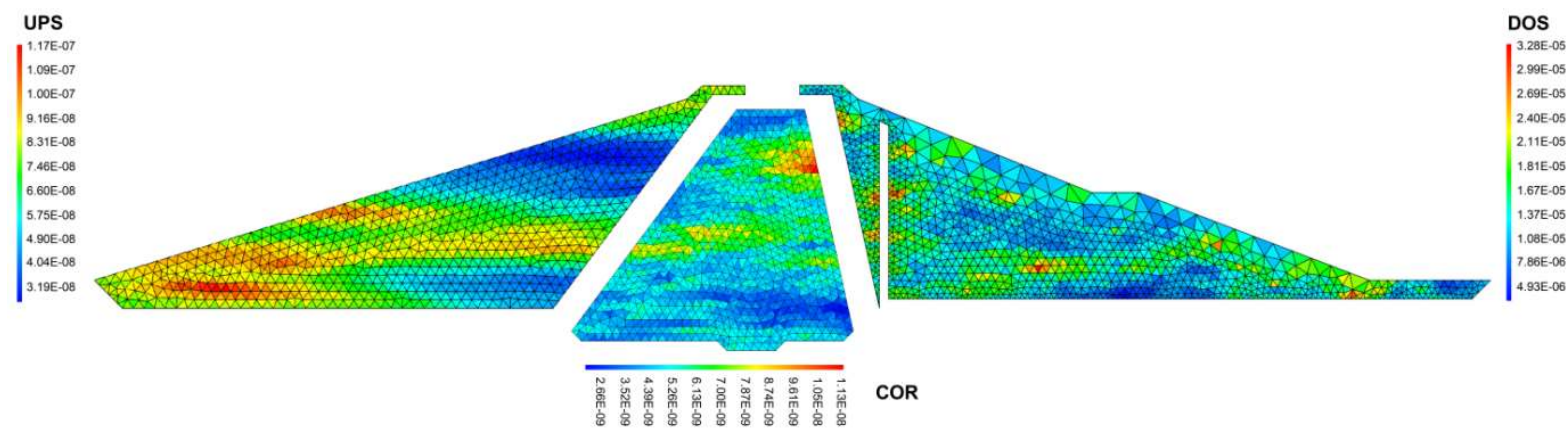

343 Fig. 7. Example of realization of a random field of permeability (in $\mathrm{m} / \mathrm{s}$ ).

\section{NUMERICAL CALCULATIONS OF THE PORE WATER PRESSURE AND RESULTS}

\subsection{Deterministic analysis results}

347 The deterministic seepage analysis is done using the FE code Cast3M. This code allows

348 the integration of user-developed procedures which is highly beneficial for probabilistic 349 analysis.

350 Thus, before considering the probabilistic model, it was necessary to verify that the 351 developed hydraulic model based on FEM gave acceptable results during a deterministic 352 seepage calculation in which the permeability was considered constant. This is here done with 353 the commercial seepage analysis software SEEP/W (GeoStudio). 
The values of the vertical permeability chosen for each of the materials corresponded to 355 orders of magnitude of permeabilities measured in the different zones, with values of $5 \times 10^{-}$ $356{ }^{9} \mathrm{~m} . \mathrm{s}^{-1}$ for the core, $5 \times 10^{-6} \mathrm{~m} \cdot \mathrm{s}^{-1}$ for the upstream shoulder and $5 \times 10^{-5} \mathrm{~m} \cdot \mathrm{s}^{-1}$ for the 357 downstream shoulder, respectively. Anisotropy coefficients of 2 and 5 are respectively taken 358 for the shoulders material (UPS and DOS) and the core material (COR). Regarding the 359 foundation, the permeability considered was taken as equal to $1 \times 10^{-6} \mathrm{~m} \cdot \mathrm{s}^{-1}$. A sensitivity 360 analysis showed that a variation of this value with a factor from 1 to 10 influenced slightly the 361 phreatic surface. Regarding the drain, a value of $1 \times 10^{-4} \mathrm{~m} \cdot \mathrm{s}^{-1}$ was taken, corresponding to the 362 permeability of a coarse material. In this application, an unsaturated behavior of the materials 363 was considered with the Van Genuchten model described by Eqs. (2) and (3). The 364 deterministic values of the parameters $\alpha$ and $n$ are listed in Table 2. These values are obtained 365 from the available GSDC using the methodology described by Gupta and Larson (1979). Here 366 again, a sensibility analysis was performed to show that the location of the phreatic surface is 367 not significantly influenced by the range of values of $\alpha$ and $n$ obtained from the GSDC.

368 The geometry used in the hydraulic model is presented in Fig. 8. The meshing of the 369 structure and the foundation was composed of 12666 triangular elements. Each element is 370 composed of 7 nodes: three arranged at the corners of the element, three in the center of the 371 faces and one on the center of the element.

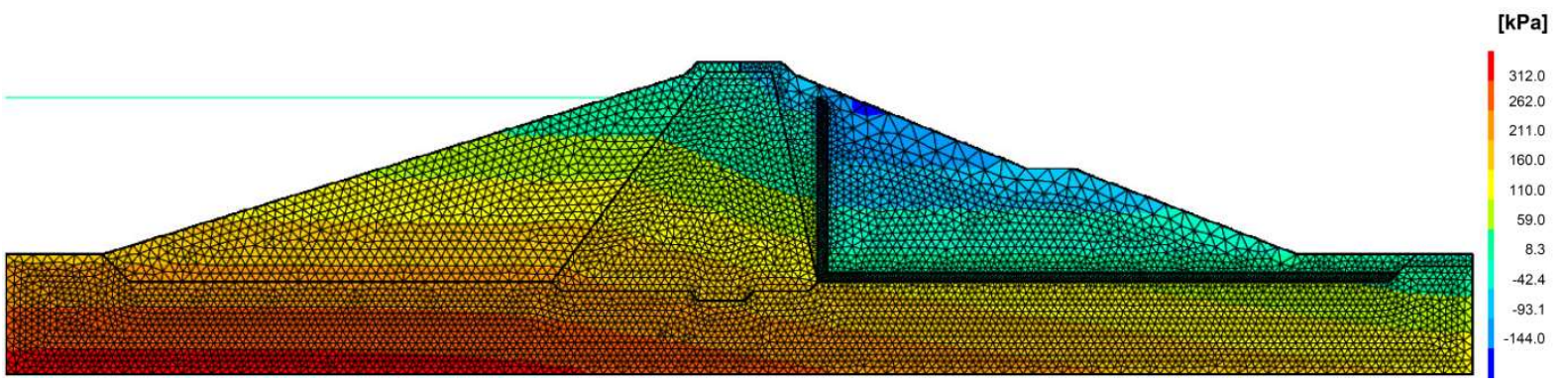

373 Fig. 8. Deterministic analysis - Pore water pressures field (Cast3M). 
The upstream boundary condition corresponds to the normal water level of the reservoir.

375 The results obtained from the deterministic analysis are shown in Fig. 8. The pressure profiles 376 plotted in Fig. 9 confirm that the results obtained from model developed with Cast3M are 377 very similar to those obtained using SEEP/W, which permitted validating the FE model.

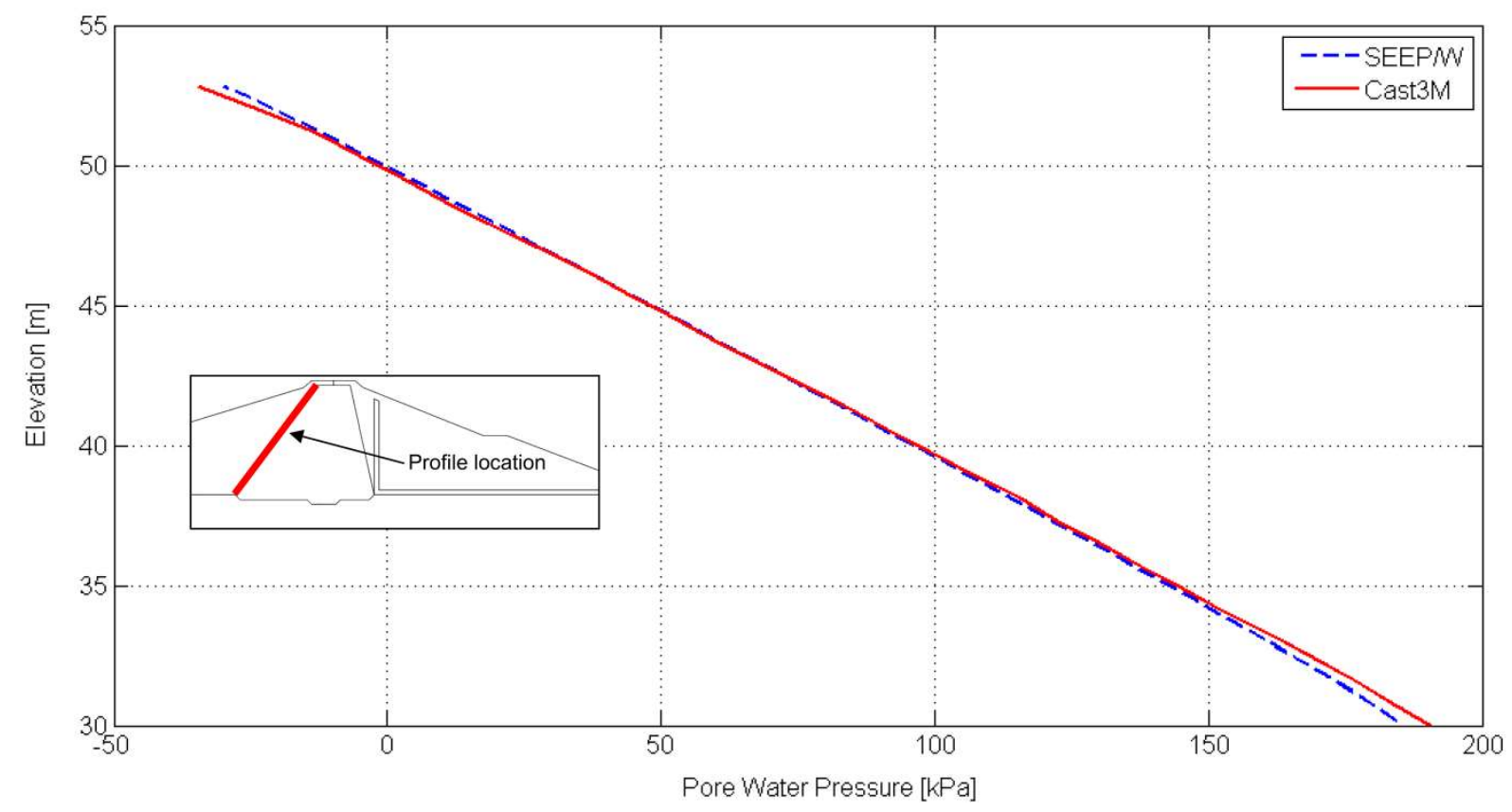

379 Fig. 9. Deterministic analysis - Comparison of Cast3M/SEEP pressure profiles.

\subsection{Monte-Carlo simulation results}

In this application, the reliability open-source software OpenTURNS is used to perform the MCS from the FE model developed with Cast3M.

Firstly, the grain size distribution curve and the liquid limit of the two materials are randomly generated with OpenTURNS. The specific surfaces $S_{S_{-} G S D C}$ and $S_{S_{-} L L}$ and the fraction of fines $p$ are calculated using the sampled values. The weighted specific surfaces of the shoulder and core materials could then been computed.

Secondly, a realization of the random field of dry density is generated with FE code Cast3M. Then, this random field is coupled with the weighted specific surface values to deduce the random field of permeability. 
Concerning the anisotropy, the data available in the case study did not permit using a

391 random procedure to characterize the anisotropy coefficients of the materials. In order to 392 consider a significant range of uncertainty, these coefficients are therefore represented by 393 truncated normal distributions as described in Table 2. The lower limit of these distributions is 3941 in order to ensure that the horizontal permeability is always higher than the vertical 395 permeability. The upper limit is chosen to avoid excessive contrasts between these two 396 permeabilities, according to the literature (Smith and Konrad, 2011; Leroueil et al., 2002).

397 The flow equation is resolved by the FE model and a pore-water pressure field is obtained.

398 The pressures calculated at the same locations that the pressure cells on the real structure are 399 extracted to be compared to the monitoring measurements made in the field. The coordinates 400 of the phreatic surfaces are also obtained.

5000 simulations are performed in this study. Convergence of the statistics (mean and 402 standard deviation) of pore water pressure is obtained on each location of the pressure cells. 403 Fig. 10 shows the convergence for the pore water pressure computed on cell PX/2.

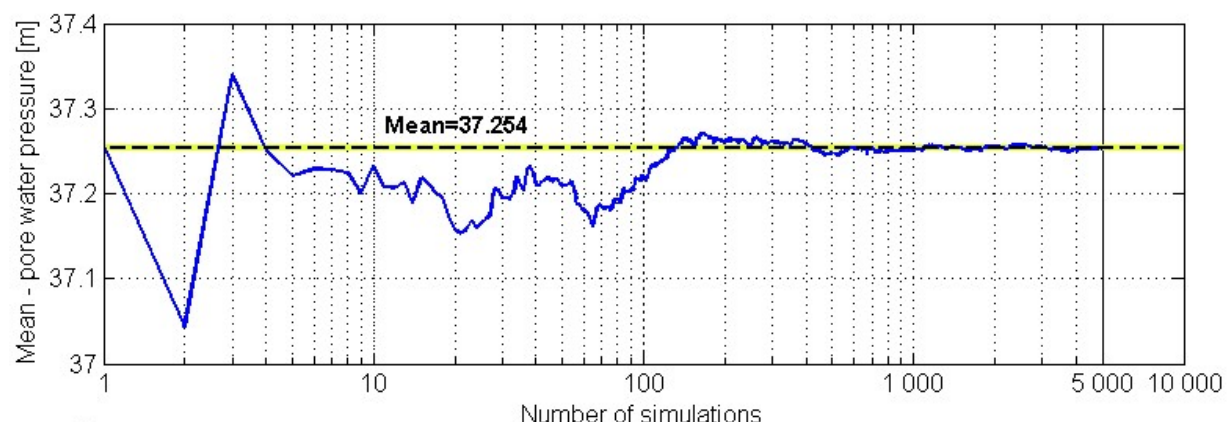

a.

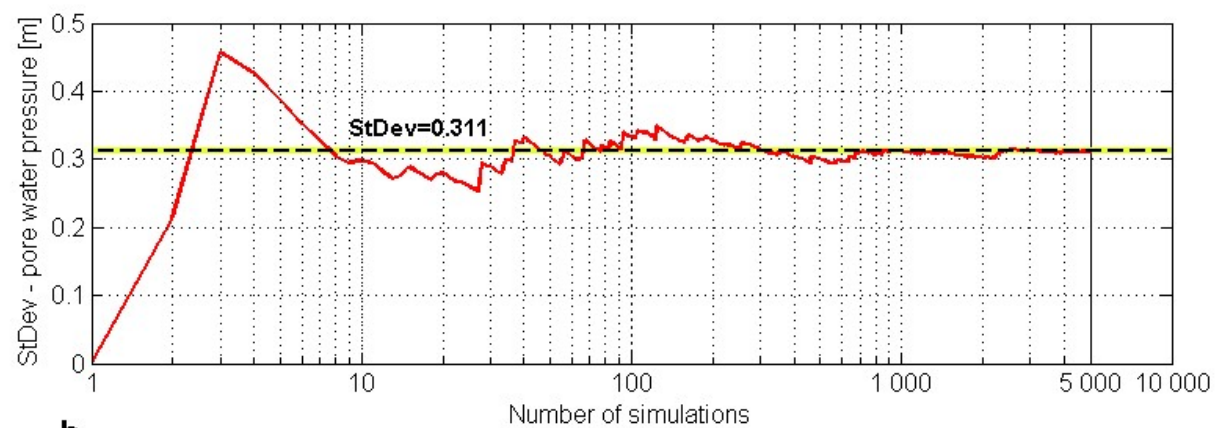

404

b. 
405 Fig. 10. Convergence of the mean and the standard deviation of the pore water pressure 406 calculated at cell PX/2. a. Mean vs. number of simulations. b. Standard deviation vs. number 407 of simulations.

\subsection{Comparison of pore water pressure modelling VS monitoring data}

Fig. 11 shows the distribution of phreatic surfaces obtained as the outcome of the MCS.

411 the ranges of variation of the phreatic surfaces between two lines representing the percentiles 412 at $5 \%$ and $95 \%$ of the modelled distribution. Finally, gray dashed lines represent the extrema 413 of the distribution of phreatic surfaces.

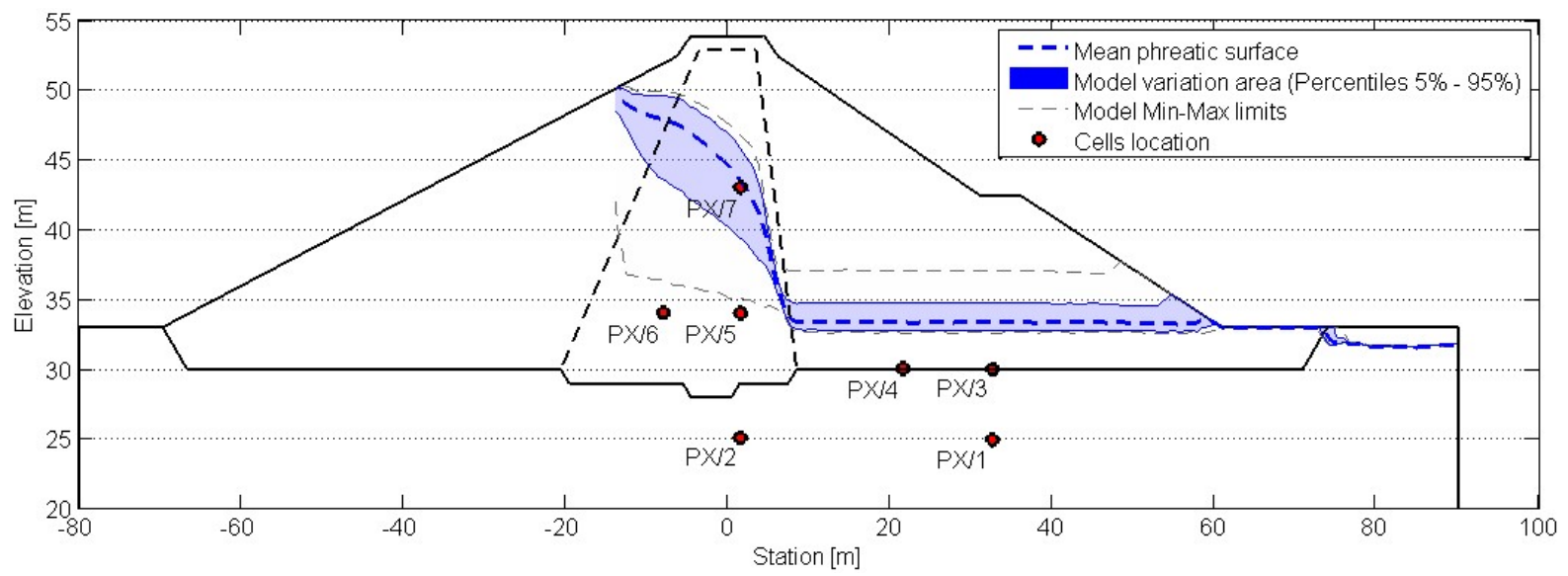

415 Fig. 11. Distribution of the phreatic surfaces as model outputs.

416 Fig. 12 represents the statistical properties (mean and standard deviation) of pore pressures

417 obtained by Monte-Carlo simulations. A sample of pore pressures is calculated on each node 418 of the mesh. Fig. 12 is obtained by computing the mean and the standard deviation of each of 419 these samples. 
a.

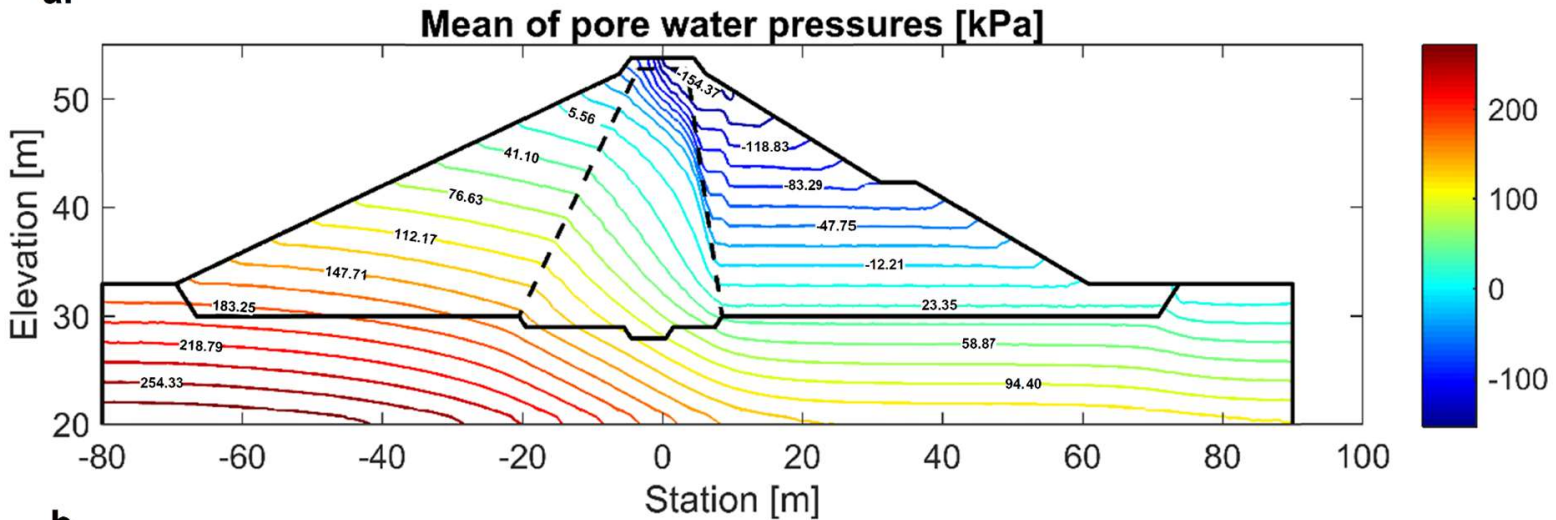

b.

Standard deviation of pore water pressures [kPa]

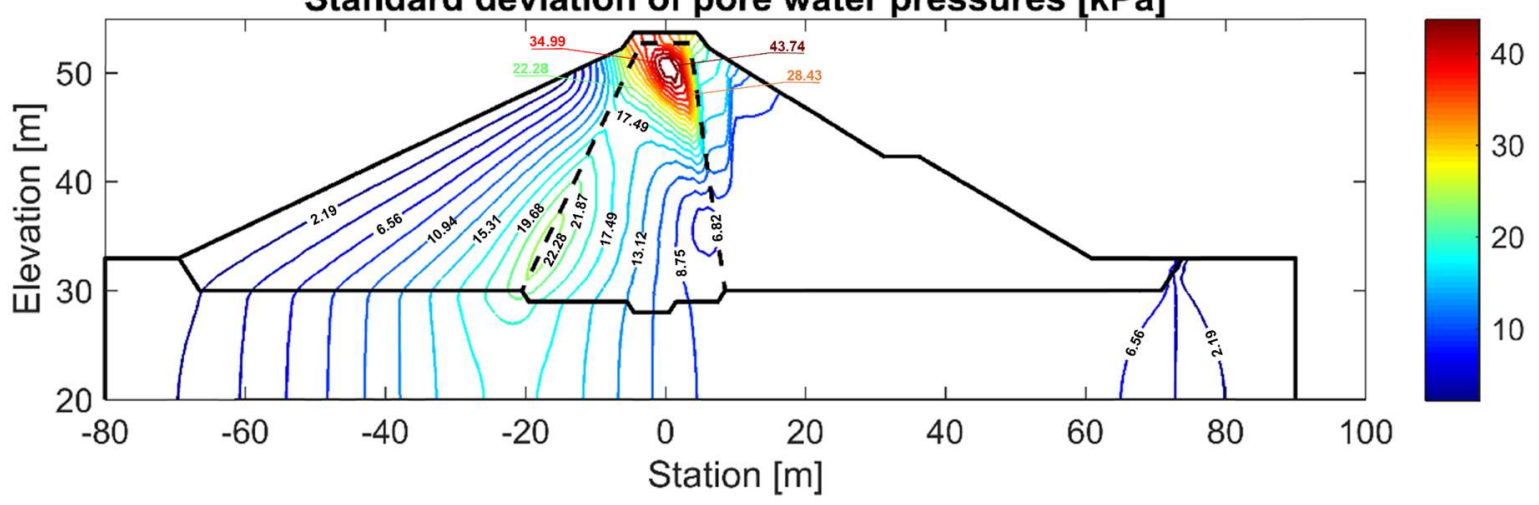

421 Fig. 12. Mean and standard deviation of pore water pressures obtained by Monte-Carlo

422 simulations.

423 Finally, Fig. 13 allows the comparison between measured and calculated distributions of

424 pore water pressures on the different cells in representing theirs means and the percentiles at

$4255 \%$ and $95 \%$. The distributions of the measured pressures on cells $\mathrm{PX} / \mathrm{Y}$ correspond to the

426 aggregation of the measurements realized on the three monitoring profiles when the height of

427 the reservoir was close to its normal operating level, in order to be consistent with the

428 boundary conditions of the model. The blue color is dedicated to the measured values whereas

429 the red color is specific to the calculated values. 


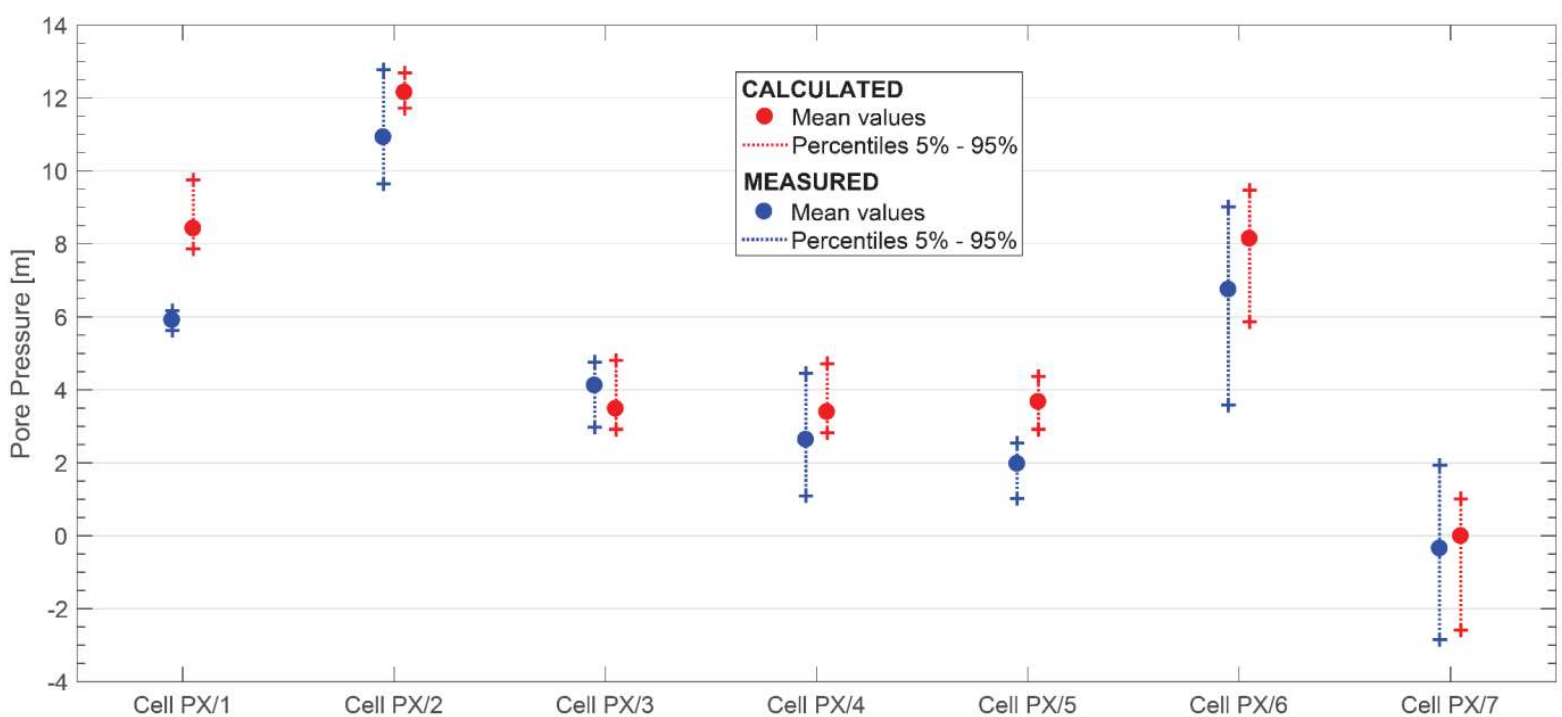

431 Fig. 13. Comparison between measured (monitoring) and calculated (model) distributions.

\section{DISCUSSION}

\subsection{Discussion on probabilistic modelling of pore water pressures}

A probabilistic modelling for representing the spatial variability of pore water pressure was carried out in this study for the case of an existing earth dam.

437 large number of soil properties data available on the dam (including numerous compaction

438 control measures). In the probabilistic methodologies available in the literature, probability 439 laws are fitted to data when the latter are considered, but in the more usual case, they are 440 taken arbitrarily from reference sources. The implemented procedure makes use of both the 441 available data stemming from abundant measures performed during construction, and design 442 data from the laboratory. This article shows that it is possible to give a relatively consistent 443 probabilistic modelling of the pore water pressures in an earth dam with soil properties dataset 444 available on the structure. 
The quantity of soil properties data available on the dam considered nonetheless influences the quality of the results obtained using the probabilistic approach. The internal spatial variability of the earth dam can be evaluated by parameters subject to a large number of measures in the field, as in the case of soil compaction control measures. For the other parameters measured (liquid limit, grain size characteristics, etc.), the values available are often relatively rare, which makes statistical quantification difficult.

The probabilistic modelling of pore water pressures implemented on this case study does not directly involve the variables of interest (i.e. the permeability of the materials), because they are not available in enough quantities to perform a geostatistical analysis. Therefore, the use of empirical relations is required to evaluate these variables of interest on the basis of variables measured in the field, for which numerous data can be supplied. For example, in the case study considered here, the assumption made on the estimation of the specific surface provided consistent values but they were not validated by precise measures performed in the laboratory by gas adsorption or with compounds like methylene blue (Konrad and Gabezas, 2008), since these tests are rarely carried out in earth dam projects. Besides, the use of empirical relations, as the Kozeny-Carman equation described by Eq. (5), involves errors due to transformation uncertainty and this issue has not been broached in this article. Taking into 462 account the uncertainties inherent to model errors is therefore a possible path for this research work, on the basis of the work proposed by (Phoon and Kulhawy, 1999) for example.

464 Another hypothesis is made about the choice of the autocorrelation function used to model 465 the spatial variability. In our case, if Gaussian or spherical models are chosen instead of the 466 exponential model, the vertical and horizontal autocorrelation lengths will be respectively 467 equal to $l_{X}=6.7 \mathrm{~m}$ or $4.7 \mathrm{~m}$ and $l_{Z}=1.6 \mathrm{~m}$ or $1.2 \mathrm{~m}$ instead to $l_{X}=4.9 \mathrm{~m}$ and $l_{Z}=1.9 \mathrm{~m}$ in the exponential case. These results from different autocorrelation functions are of the same order 
470

amount of data is necessary to obtain relevant variograms which will give the best autocorrelation function to be used by fitting different models.

Finally, the use of truncated distribution may be questioned. This hypothesis is made in this specific case in order to be as much as possible within the variation range of each parameter. However, this choice may have an impact on the results. More calculations are needed to evaluate this influence. Indeed, in this article, the implemented methodology prevails over the results.

\subsection{Discussion on the results}

As seen on Fig. 11, the variation of the modelled phreatic surfaces is logical: the mean phreatic surface corresponds to the one expected on this type of dam. The variation area between the 5\% and $95 \%$ percentiles (colored in blue) is relatively narrow and stays consistent with the permeability variation. The fluctuation is logically larger into the core of the dam rather than into the downstream shoulder because of the drainage system which tends to concentrate the phreatic surfaces.

Fig. 12a shows that the mean field of pore pressures obtained after Monte-Carlo simulations is, as expected, close to the deterministic one (see. Fig. 8). Fig. 12b gives interesting information about the spatial variability of pore water pressures within the dam, expressed in standard deviations. The areas of highest variability of pore water pressures (i.e., with the highest standard deviations) are mostly located on the upper part of the core, where the phreatic surfaces are the more fluctuant, as shown by Fig. 11. This is due to the gradient of hydraulic conductivity between the upstream shoulder and the core which can be important or not, depending on the values of hydraulic conductivities obtained during the simulations. The standard deviation values decrease towards the edges with boundary conditions (where 
493 logically the standard deviation becomes zero) as well as towards the downstream shoulder of 494 the dam where the phreatic surfaces are lowered by the drains.

The variations observed in the pore water pressures calculated from the probabilistic model depended on the MCS performed on the liquid limits and the grain size distribution curves for

497 the three materials specific to each zone of the dam. These simulations provided values of 498 specific surfaces of the grains and then hydraulic conductivities in order to calculate the pore 499 water pressure field. Despite the uncertainties brought by the procedure, the results obtained 500 for the case study after completing the probabilistic modelling of pore water pressures are 501 globally consistent with the monitoring measurements recorded for the structure, as illustrated 502 by Fig. 13. This comparison is here made only to show that the probabilistic modelling gives 503 the same order of magnitude of pore water pressure than that could be observed when 504 monitoring the dam. Indeed, the variability of the measured pore pressure is due to several 505 factors like inherent variability, climatic conditions, measurement protocol, local effects 506 around the cell, etc. These uncertainties are not taken into account in the probabilistic 507 modelling and the uncertainties relative to measured and calculated datasets are so different.

508 The means of the pore water pressure distributions resulting from the model were slightly 509 higher than those stemming from the monitoring measures (excluding cell PX/3). The 510 distributions obtained by the model appeared moreover less spread than those measured when 511 monitoring the dam. Apart from two cells $(\mathrm{PX} / 1$ and $\mathrm{PX} / 5)$, the variation ranges of the 512 calculated distributions of pore water pressures are globally included into those measured. 513 The difference observed on cells $\mathrm{PX} / 1$ and $\mathrm{PX} / 5$ can be explained by: the possible 514 malfunction of the pressure cells, and their location into the fill. For PX/5, the cells of the 515 three monitoring profiles give incoherent measurements. Indeed, on the three cells, the means 516 of the measured pressures are below the laying elevations of the cells. As for cell PX/1, this 517 cell is located into the foundation beneath the horizontal drain: the modelled pore water 
518 pressure at this point is more affected by the hypothesis made on the permeability of the

519 foundation than on the seepage itself.

520

521

523

524

\section{CONCLUSIONS}

This article presents a probabilistic approach for modelling the spatial variability of the pore water pressure of a case study of earth dam. In this approach, the spatial variability of the permeability of the materials is evaluated from statistical and geostatistical analyzes of available soil properties data. Its originality consists in basing the entire probabilistic process on the data measured in the field.

The spatial variability of the permeability was determined using the physical parameters of the materials modelled as random variables and using the spatial variability of dry density measured for the structure during compaction controls.

A finite element hydraulic model of the dam studied was developed using the FE code Cast $3 \mathrm{M}$ to calculate the pore water pressure field on the basis of the hydraulic conductivity random field obtained after treating the available data. MCS were then performed to evaluate the spatial variability of the pore water pressure field.

The probabilistic analysis gives distributions of pore water pressure and phreatic surfaces. These distributions were compared to those of the monitoring measures performed on the dam in the case study. The probabilistic analysis gives the pressures and phreatic water surfaces within a range of variation in agreement with the field measurements.

Improvements to this probabilistic approach can be considered. Indeed, the errors of the model can be integrated in a permeability evaluation process to take into account uncertainties linked to the calculation hypotheses. Otherwise, the methodology implemented on the case 
540 541 number of data available.

542 according to the approach described in this article.

\section{6}

study could also be adapted to a large number of earth dams as a function of the type and

Finally, this work is part of a wider study aimed in coupling hydraulic calculations with those of the mechanical stability to determine the reliability of the structure. In this perspective, the mechanical model will integrate the pore-water pressure field obtained

\section{AKNOWLEGMENTS}

The authors gratefully acknowledge the engineers of the Compagnie d'Aménagement des Coteaux de Gascogne (CAGC) for having graciously supplied the monitoring data of the dam studied in this article. Irstea and Clermont-Auvergne University are also thanked for funding.

\section{REFERENCES}

Bergado DT, Anderson LR. Stochastic analysis of pore pressure uncertainty for the probabilistic assessment of the safety of earth slopes. Soils Found, 1985; 25(2):87-105.

Castelier E. Estimation of a permeability field from piezometric head measurements (in French). PhD Thesis, Ecole des Mines de Paris, France; 1995.

Chapuis RP, Legare PP. A simple method for determining the surface area of fine aggregates and fillers in bituminous mixtures. Effects of aggregates and mineral fillers on asphalt mixture performance. ASTM STP 1992; 1147:177-86.

Chapuis RP, Aubertin M. On the use of the Kozeny Carman equation to predict the hydraulic conductivity of soils. Can Geotech J 2003; 40(3):616-28.

Chapuis RP. Predicting the saturated hydraulic conductivity of soils: a review. B Eng Geol Environ 2012; 71(3):401-34, doi: 10.1007/s10064-012-0418-7.

Cho SE. Probabilistic analysis of seepage that considers the spatial variability of permeability for an embankment on soil foundation. Eng Geol 2012; 133-134:30-39, doi: 10.1016/j.enggeo.2012.02.013.

Dolinar B. Predicting the hydraulic conductivity of saturated clays using plasticity-value correlations. Appl Clay Sci 2009; 45(1-2):90-4, doi: 10.1016/j.clay.2009.04.001.

Fenton GA, Griffiths DV. Statistics of block conductivity through a simple bounded stochastic medium. Water Resour Res 1993; 29(6):1825-30.

Fenton GA, Griffiths DV. Statistics of free surface flow through stochastic earth dam. J Geotech Eng 1996; 122(6):427-36. 
Fenton GA, Griffiths DV. Extreme hydraulic gradient statistics in stochastic earth dam. J

572 Geotech Geoenviron Eng 1997; 123(11):995-1000.

573 Fooladmand HR. Estimating soil specific surface area using the summation of the number of 574 spherical particles and geometric mean particle-size diameter. Afr J Agric Res 2011; 575 6(7):1758-62.

576 Foster M, Fell R, Spannagle M. The statistics of embankment dam failures and accidents. Can 577 Geotech J 2000; 37(5):1000-24.

578 Fredlund DG, Xing A. Equations for the soil-water characteristic curve. Can Geotech J 1994; 579 31(4):521-32.

580 Fredlund MD, Fredlund DG, Wilson GW. An equation to represent grain-size distribution. 581 Can Geotech J 2000; 37(4):817-27.

582 Fredlund DG, Houston SL. Protocol for the assessment of unsaturated soil properties in 583 geotechnical engineering practice. Can Geotech J 2009; 46(6):694-707.

584 Griffiths DV, Fenton GA. Three-dimensional seepage through spatially random soil. J 585 Geotech Geoenviron Eng 1997; 123(2):153-60.

586 Gui S, Zhang R, Turner JP, Xue X. Probabilistic slope stability analysis with stochastic soil 587 hydraulic conductivity. J Geotech Geoenviron Eng 2000; 126(1):1-9.

588 Gupta SC, Larson WE. Estimating soil water retention characteristics from particle size 589 distribution, organic matter percent, and bulk density. Water Resour Res 1979; 15(6):1633-35

590 Huang J, Griffiths DV, Fenton GA. Probabilistic analysis of coupled soil consolidation. J 591 Geotech Geoenviron Eng 2010; 136(3):417-430.

592 Konrad JM, Gabezas FAV. Caractérisation des particules fines d'un matériau granulaire de 593 fondation par l'essai au bleu de méthylène: GCT-2008-01; Québec: Université Laval; 2008.

594 Leroueil S, Le Bihan JP, Sebaihi S, Alicescu V. Hydraulic conductivity of compacted tills 595 from northern Quebec. Can Geotech J 2002, 39(5):1039-49. Li DQ, Jiang SH, Cao ZJ, Zhou W, Zhou CB, Zhang LM. A multiple response-surface method for slope reliability analysis considering spatial variability of soil properties. Eng 598 Geol 2015; 187:60-72.

599 Liu LL, Cheng YM, Jiang SH, Zhang SH, Wang XM, Wu ZH. Effects of spatial 600 autocorrelation structure of permeability on seepage through an embankment on a soil 601 foundation. Comput Geotech 2017; 87:62-75.

602 Masekanya JP. Stabilité des pentes et saturation partielle-Etude expérimentale et modélisation 603 numérique. $\mathrm{PhD}$ Thesis, Liège University, Belgium, 2008.

604 Phoon K.K., Kulhawy FH. Evaluation of geotechnical property variability. Can Geotech J, $6051999 ; 36(4): 625-39$.

606 Pilot G, Amar S, Le Roux A. Relations entre la composition minéralogique et les 607 caractéristiques mécaniques de quelques sols argileux français. Bull. de Liaison de 608 Laboratoires Routiers 1970, Ponts et Chaussées, 43.

609 Richards LA. Capillary conduction of liquids through porous mediums. J Appl Phys 1931; 610 1(5):318-33.

611 Sivakumar Babu GL, Murthy DS. Reliability analysis of unsaturated soil slopes. J Geotech 612 Geoenviron Eng 2005; 131(11):1423-28. 
613 Smith M, Konrad JM. Assessing hydraulic conductivities of a compacted dam core using 614 geostatistical analysis of construction control data. Can Geotech J 2011; 48(9):1314-27, doi: $61510.1139 / \mathrm{t} 11-038$.

616 Srivastava A, Babu GLS, Haldar S. Influence of spatial variability of permeability property on 617 steady state seepage flow and slope stability analysis. Eng Geol 2010; 110(3-4):93-101, doi: 618 10.1016/j.enggeo.2009.11.006.

619 Sudret B, Der Kiureghian A. Stochastic finite element methods and reliability: a state-of-the620 art report: Department of Civil and Environmental Engineering, University of California; 6212000.

622 Van Genuchten MT. A closed-form equation for predicting the hydraulic conductivity of 623 unsaturated soils. Soil Sci Soc Am J 1980; 44(5):892-98.

624 Vanmarcke EH. Random Fields: Analysis and Synthesis, MIT Press, Cambridge, MA; 1983.

625 Yang HQ, Zhang L, Li DQ. Efficient method for probabilistic estimation of spatially varied 626 hydraulic properties in a soil slope based on field response: a Bayesian approach. Comput 627 Geotech 2018; 102:262-272.

628 Zheng D, Huang J, Li DQ, Kelly R, Sloan SW. Embankment prediction using testing data and 629 monitored behaviour: A Bayesian updating approach. Comput Geotech 2018; 93:150-162. 